\title{
Humanismo y universalidad en el teatro de Terencio
}

\author{
JOSÉ RIQUELME OTÁLORA \\ Departamento de Ciencias de la Antigüedad \\ Area de Filología Latina \\ Facultad de Filosofía y Letras \\ Universidad de Zaragoza (España)
}

\begin{abstract}
RESUMO: A comédia romana com cerca de uma dezena de tipos convencionais pode ser considerada como um reflexo da história social e econômica do mundo clássico, não recolhida ou sistematizada:por historiadores antigos. Os dois grandes comediógrafos que escreveram em língua latina conferem, porém, um tratamento completamente diferente a essas personagens convencionais; tratamento consoante com o caráter e finalidade da obra de cada um deles: enquanto Plauto se propõe divertir sua audiência, Terêncio se empenha em remodelar os mais delicados sentimentos da alma humana. Este trabalho pretende analisar e esclarecer os procedimentos técnicos dos quais se serve o segundo dramaturgo para humanizar ao máximo as situações do seu teatro. O relevante das observações que fazemos consiste, em nossa opinião, em ter estabelecido as bases explicativas das influências terencianas na tradição clássica da posterior dramaturgia européia, não só medieval e renancentista, como também moderna e contemporânea.
\end{abstract}

PALAVRAS-CHAVE: Terêncio, técnicas de caracterizaçãoo moral, humanismo, tradiçao clássica.

Desde hace aproximadamente un siglo las nuevas orientaciones de la Historia vienen reprochando a los investigadores y estudiosos de esta ciencia el haberla reducido, hasta entonces, tan sólo a príncipes y batallas sin haber tenido en cuenta para nada al verdadero actor protagonista que la muchedumbre popular ha sido, esto es, los esclavos, artesanos, labradores, publicanos y comerciantes. Y es precisamente este reproche el que en nuestros días ha llevado al profesor Agustín García Calvo (García Calvo, 1971, p.3), entre otros, a sostener la tesis de que, al prescindir de la dinámica social de las clases populares, las batallas y los príncipes no pasan de formar, dentro del cuadro general del hecho histórico, un frívolo anecdotario.

Partiendo de esta consideración el mencionado profesor $($ ibid.) llega a afirmar que "... la comedia romana es con mucho, por lo que al mundo antiguo toca, el más rico documento de esa historia no escrita...", ya que viene a ser "el arte destinado a dotar de facciones a los seres sin rostro de las calles y casas en tanto que se olvida hasta lo sorprendente de aquella otra historia 
pública que en los aledaños de sus escenarios se representaba".

Con esta apreciación conviene de algún modo el juicio de Terencio cuando indirectamente declara que la vida misma es fuente esencial de inspiración para él y otros autores de comedias:

Quod si personis isdem huic uti non licet,
qui magis licet currentem seruom scribere,
bonas matronas facere, meretrices malas,
parasitum edacem, gloriosum militem,
puerum supponi, falli per seruom senem,
amare, odisse, suspicari? (Eun. vv.35-40)

"Y si no le está permitido al comediógrafo servirse de los personajes ya utilizados (por autores precedentes)/ ¿ Cómo podría por demás hacer aparecer en su obra a un esclavo que por todas partes se hace visible,/ componer el papel de las buenas madres de familia, el de las pérfidas cortesanas,/ el del parásito glotón, el del soldado petulante,/ lograr que la identidad de un niño sea suplantada, y que un anciano sea objeto de tomadura de pelo por parte de su esclavo?/ ¿Cómo podría representar, si no, amoríos, aversiones, recelos?"’

En consecuencia, según el ya citado autor (García Calvo, 1971, p. 3-4), un análisis sociológico de la comedia romana permite vislumbrar en ella los tres grados de riqueza en que aparece distribuida la sociedad libre de la época reflejada en este teatro: el primero lo compondrían potentes millonarios, dueños de tierras y fletadores de navíos; el segundo, honradas damas en apuros obligadas a ganarse el pan con la hilatura de sus manos; el tercero, finalmente, antiguos ricos venidos a menos hasta incurrir en la mendicidad y el parasitismo.

Entre dicha sociedad libre y sus esclavos se desenvuelve la trama cómica.

I. Dentro de la producción literaria de la antigua Roma -y atendiendo a las comedias conservadas-, Plauto y Terencio son los más destacados representantes del género.

Coinciden ambos autores en dos puntos: primero, en haberse dedicado exclusivamente a la comedia, frente a la mayoría de dramaturgos de su tiempo que también cultivaron la tragedia; y segundo, en haber tomado como modelo los mismos originales de la Comedia nueva griega.

Por lo demás, numerosas son las diferencias que los separan en toda la gama de aspectos del arte dramático, (Riquelme Otálora, 1985, p. 14-29).

De estas diferencias dejamos de lado en la ocasión presente las que se refieren al distinto tratamiento que uno y otro autor hacen de los comunes modelos griegos y las que atañen tanto al desarrollo de la acción dramática como a la consecución del efecto cómico: pues, aunque no negamos la capital importancia de estas facetas, quedan, sin embargo, un tanto al margen del objeto de este trabajo.

Por tanto, tan sólo estableceremos aquí los diferentes matices psicológicos con que representan a los mismos personajes convencionales uno y otro comediógrafo, ya que se centrarán fundamentalmente en este punto nuestras ulteriores consideraciones. ${ }^{2}$

Y así pues, siguiendo más o menos de cerca el estudio que sobre este punto hace Lisardo Rubio, en el prólogo a su edición de Terencio (Rubio Fernández, 1966, v.1, p. XLIV-XLVI), notamos que:

Los jóvenes galanes tienen en Terencio las características pasión y fogosidad, propias de la edad, que los emparentan con los personajes análogos plautinos, pero, a diferencia de éstos, corresponden con respeto y afecto a la digna actitud de los padres; actitud ésta que en Plauto brilla por su ausencia. De forma distinta a los plautinos los jóvenes terencianos se contienen y llegan al arrepentimiento ante la autoridad paterna. En este sentido Quereas en Eunuchus, Pánfilo en Andria y Esquino en Adelphoe son verdaderas creaciones del poeta cómico africano.

El parásito en Terencio es algo más que el vulgar hambriento plautino, dispuesto a cualquier humillación por cazar un plato suculento. Los parásitos en Terencio son finos epicúreos que se 
hacen apreciar por su hábil adulación (caso de Gnatón en Eunuchus) o por su genio inventivo (caso de Formión).

El soldado, aunque tan grotesco en líneas generales como el de Plauto, también sufre algunos cambios en Terencio: Trasón, el soldado fanfarrón de Eunuchus, es un vanidoso, pero sin incurrir jamás en los extremos y ridiculeces del Pirgopolinices de Plauto.

El papel de los padres en Plauto (salvo el caso de Hegión en Captiui) nos ofrece una triste imagen del cabeza de familia en la sociedad romana de entonces: no tienen noción de la responsabilidad que sobre ellos recae en la educación de los hijos; por el contrario, imitan a éstos en sus desordenadas andanzas y, llegado el caso, se benefician de las amantes de sus hijos, como puede verse en Bacchides; otras veces no quieren que los muchachos vayan a parar a sus propios desórdenes, pero entonces los guía la avaricia y no la noción superior del deber moral. Los padres en Terencio no carecen ciertamente de defectos: han tenido en el pasado, o tienen en el transcurso de la acción, debilidades reprobables, pero conservan el pudor ante los hijos, cuya vida moral les preocupa hondamente; sus métodos educativos no suelen ser acertados, ya que se muestran demasiado fáciles e indulgentes unas veces, como Mición en Adelphoe; otras, demasiado severos y hasta rudos, como Demeas en la misma obra o Menedemo en Heautontimorumenos; pero jamás pierden la noción básica de su misión educadora, precisamente lo que más falta en el mundo plautino y cuya carencia en éste constituye su mayor depravación.

El lenón tan sólo aparece en dos breves escenas de Terencio y deja de ser repugnante como el de Plauto.

Las matronas, más numerosas en la obra de Terencio que en la de Plauto, a pesar de ser esta última tan superior a la de Terencio en extensión, forman en el comediógrafo africano, una agradable colección. El bello sexo encontró en Terencio un abogado poco común en la Literatura. Las matronas en Plauto, excepto Alcmena en Amphitruo, son hurañas, ásperas, altivas, dominantes y derrochadoras. En Terencio todas son delicadas y encantadoras: virtuosas y comprensivas con sus maridos, llenas de ternura para con los hijos y sacrificadas por ellos. Hasta Nausístrata en Phormio, que es rica y caprichosa como sus hermanas plautinas, enfurecida ante la infidelidad de su marido, no tarda en sobreponerse a la cólera: se reconcilia con él y usa de su influencia para interceder por cuantos viven a su alrededor.

La doncella, al ser el personaje que menos interviene en el entramado de la obra, juega un papel tan exiguo en ambos autores que su actuación no produce ningún contraste significativo en cuanto al modo de ser tratado por cada uno de ellos.

Los esclavos en Terencio conservan toda su habilidad e inventiva tradicionales, pero aparecen exentos del cinismo, grosería y desfachatez con que los vemos actuar en Plauto; en Terencio nunca ridiculizan las debilidades de sus amos, a quienes sirven siempre respetuosos y sumisos, con una fidelidad que se eleva a veces hasta el sacrificio; han adquirido cierto decoro y señorío, delicadeza de sentimientos y urbanidad en el trato con sus dueños.

Las mismas cortesanas que en Plauto son todo egoísmo, avidez, vileza, voluptuosidad y perfidia, aparecen en Terencio adornadas de cualidades notables: son educadas, de finos sentimientos e ideas humanitarias, y sólo un hombre es objeto de sus amores; en medio de la atmósfera viciada que respiran, no han degenerado hasta perder el sentimiento de la virtud.

Ahora bien, según nosotros mismos tuvimos ocasión de estudiar en el trabajo que supuso nuestra Memoria de Licenciatura ${ }^{3}$, el contraste más significativo entre Plauto y Terencio, dentro del elenco de personajes que venimos enumerando, es el producido por la relación inversa que, en lo que a caracterización y comicidad se refiere, establecen ambos autores entre las figuras de los esclavos y parásitos:

En Plauto el esclavo se manifiesta como el mayor soporte de la fantasía cómica de la pieza; el parásito, en cambio, asume un papel irrelevante en este sentido. Por el contrario, Terencio 
invierte las tornas y, si en su obra los esclavos han perdido uis comica frente a sus congéneres plautinos, este efecto ha sido contrarrestado por el desplazamiento del recurso de la comicidad hacia la figura del parásito; desplazamiento que produce una mayor importancia, en relación a Plauto, del papel de este personaje en las comedias terencianas.

Esta observación halla su explicación en la distinta finalidad de la obra de uno y otro autor:

Plauto, afanoso de buscar situaciones cómicas, encuentra en el esclavo el personaje adecuado para tal fin, precisamente por su calidad socarrona de seruus currens, mientras que del parásito hace, en un plano secundario, un personaje comodín, destinado simplemente a prestar sus servicios a otros a cambio de sabrosos manjares; $y$, aunque su glotonería no está exenta de un cierto efecto cómico, éste es muy inferior, sin embargo, a aquella otra comicidad con que Plauto caracteriza al esclavo.

La obra de Terencio, por el contrario, reviste tonos moralizantes: hemos dicho que el esclavo en ella adquiere una finura de sentimientos ajena al personaje análogo plautino, pero este logro conlleva a su vez la pérdida de buena parte de la inventiva tradicional de la caractización del papel y, en definitiva, de la fuerza cómica de que Plauto lo dotaba.

De forma paralela el parásito también se refina en Terencio. Sin embargo, este refinamiento de su tipificación, puesto al servicio de la finalidad de subsistir a costa de los demás, le hace manifestarse, de manera inversa al tratamiento que del mismo personaje hace Plauto, como un pícaro taimado que con sus tretas y artimañas absorbe en su actuación la mayor parte de la poca fuerza cómica del comediógrafo africano; absorción que llega al extremo de hacernos afirmar que es el parásito el personaje más cómico de Terencio.

En consecuencia, la proporcionalidad del efecto cómico en las figuras de los esclavos y parásitos del teatro de los dos autores que comparamos, podemos establecerla, más o menos aproximadamente, del siguiente modo:

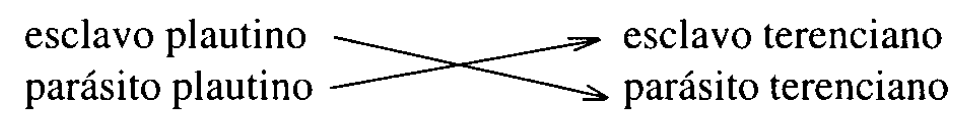

Con lo que resulta que dicha proporcionalidad es completamente inversa entre los cuatro términos establecidos.

Tras estas observaciones sobre el contraste notado en todos los tipos convencionales que comúnmente aparecen en la obra de los dos autores comparados, nos es posible sostener que todas las clases sociales quedan suavizadas y pulidas en el teatro de Terencio, dramaturgo que muy bien supo trasladar a sus comedias una pintura sin igual de aquella sociedad romana en la que él mismo se movía; sociedad llena de pasiones muy humanas; pero, por otra parte, enamorada de la elegancia, cortesía, distinción y cultura helénicas.

Plauto, en su preocupación básica por hacer reir, carga sus comedias de una fuerza cómica que se desborda en la fantasía y arrastra a los espectadores. A diferencia suya Terencio, siguiendo más de cerca el interés de la Comedia nueva griega, está fundamentalmente interesado en presentar sobre la escena una acertada pintura de caracteres, incluso por encima de una intriga mejor o peor articulada. Así supo verlo ya en la propia antigüedad romana el mismo Varrón:

In argumentis Caecilius poscit palmam, in ethesi Terentius, in sermonibus Plautus (Sat. Menipp. 399 B).

"En los argumentos Cecilio se lleva el trofeo, en las caracterizaciones lo logra Terencio, y en los parlamentos Plauto."

Lo cierto es que Terencio tiene el mérito de haber restaurado sobre la escena romana la comedia esencialmente psicológica que en alguna medida heredó de sus modelos griegos, y de 
haber penetrado en el alma humana más hondamente que cualquier otro autor antiguo para ofrecernos una viva imagen de la vida real encarnada en el centenar de personajes dibujados en su obra. Por eso, el público inteligente, si echa de menos en Terencio la alegría y la risa franca de Plauto, también ha notado la carencia en Plauto de la cortesía, elegancia y refinamiento de Terencio: pues si Plauto divierte con la acción, Terencio encanta por su profundo estudio de los sentimientos del alma humana.

II. Ahora bien, esta observación sobre los caracteres del teatro de Terencio nos ha conducido a indagar personalmente los procedimientos técnicos de que se sirve el dramaturgo para matizar en la escena la ya aludida caracterización moral de sus personajes y remodelar así el tipo de sociedad edificante que se propone presentar (Riquelme Otálora, 1983, v. 2, p. 115-120).

Los resultados de este análisis nos han llevado a detectar en el conjunto de la obra terenciana tres técnicas de presentación de caracteres manejadas por su autor de forma más bien consciente.

El primero de estos tres procedimientos técnicos se origina cuando el personaje que se encuentra afectado por una determinada problemática recurre a desahogarse personalmente en presencia de un confidente, que normalmente sopesa el problema planteado por su interlocutor y se manifiesta precisamente como contrapunto de las ideas que éste le expone. Se establece, pues, de este modo una dicotomía ideológica entre la confesión del problema, por un lado, y las posibles soluciones que de otra parte da el confidente, por otro. Dicho de otro modo, el personaje afectado por el problema, sostiene una opinión y actitud sobre el mismo diametralmente opuestas a la opinión y actitud que, acerca de la situación expuesta por éste, manifiesta de modo análogo el confidente. Este último viene a convertirse así en el contrapunto de su interlocutor.

A título de ejemplo que ilustre esta técnica podemos aducir el comienzo de Heautontimorumenos: Menedemo, el torturador de sí mismo, ha provocado, mediante el rigor empleado en la educación de su hijo Clinias, que el muchacho se haya marchado en secreto de casa al extranjero. Menedemo se acusa de esta culpa en presencia de su comprensivo vecino Cremes y declara que, por ello, él, padre tardíamente arrepentido de su conducta pasada, se ha impuesto ahora, como castigo expiatorio, trabajar día y noche sin descanso un campo, a pesar de su avanzada edad. El confidente Cremes trata de disuadirlo de esta penitencia estéril e intenta inculcarle la feliz esperanza de que el joven muy pronto regresará de nuevo a casa, aconsejándole que en lo sucesivo sea indulgente con la posible conducta desatinada del hijo (vv. 53-167).

Así pues, en el teatro de Terencio, el personaje que atraviesa una situación conflictiva, casi nunca recurre al monólogo en solitario para dar a conocer al espectador el fluir de sus sentimientos.

La forma expositiva de monólogo en solitario la emplea Terencio tan sólo en una escena de Adelphoe (vv. 26-77), aparte ya de unos pocos monólogos aclaratorios que aparecen en escenas introductorias de otras obras.

Centrándonos en el caso concreto del aludido monólogo en solitario de Adelphoe, vemos que Mición se queja de que su hijo Esquino no ha regresado a casa en toda la noche.

Ahora bien, al analizar este monólogo, no sólo podría justificarse que un padre en tal situación pueda comenzar a pensar en voz alta (lo que estaría muy acorde, por lo demás, con la ya aludida preocupación del dramaturgo por lograr una acertada pintura de caracteres), sino que también nos damos cuenta rápidamente de que el monólogo plantea por sí solo una dicotomía de posturas opuestas, semejante a la ya analizada Menedemo/Cremes en Heautontimorumenos: en dicho monólogo Mición se caracteriza a sí mismo al parangonarse con su hermano Demeas tan diferente de él. De ahí quizá el que, en este caso concreto, Terencio haya podido prescindir del confidente-contrapunto cuya opinión, en contraste con la de su interlocutor, marque una dicotomía ideológica. 
El segundo procedimiento técnico empleado por Terencio para caracterizar moralmente a sus personajes, consiste en el enfrentamiento, dentro de una misma comedia, de actitudes opuestas correspondientemente adoptadas, a lo largo de toda la obra, por dos personajes de igual condición o clase social.

Así, en el desarrollo de Adelphoe encontramos, por una parte, una oposición muy marcada entre el comportamiento de los dos viejos ya mencionados que aparecen en esta comedia, Demeas el hirsuto y Mición el indulgente; y, por otra, también notamos una oposición análoga en el talante externo que caracteriza a los dos muchachos: pues Esquino aparece como el elegante ciudadano y Tesifonte como un hombre rústico. Eunuchus opone al hermano mayor, serio y tierno, el cadete petulante. Heautontimorumenos pone en parangón a la cortesana y a la muchachita honesta. Hecyra contrapone igualmente a las dos suegras: la una rica y satisfecha de sí misma, la otra humilde y desgraciada. Luego, también esta técnica consiste, como la anterior, en el establecimiento de dicotomías mediante la oposición de personajes; oposición ahora referida a las actitudes permanentemente mantenidas por ellos a lo largo de toda la obra.

El tercer procedimiento técnico de los tres a que nos venimos refiriendo en esta parte de la exposición, consiste en los cambios más radicalizados de actitud que manifiesta el comportamiento de un mismo personaje en el transcurso de la obra; cambios que, motivados por un arrepentimiento de conducta anterior, llevan al personaje en cuestión a adoptar una postura moral diametralmente opuesta a la que hasta en un determinado momento previo su carácter hacía visible.

Ya hemos tenido ocasión de aludir al asunto de Heautontimorumenos, a propósito de explicar el primero de estos recursos: Menedemo ha provocado con su excesiva severidad que se marche de casa su hijo Clinias; pero, cuando el muchacho regresa inesperadamente, el viejo pasa de ese rigor educativo a la indulgencia total, sin lograr, así tampoco, una corrección en las costumbres disipadas del joven (vv. 410-511).

Por otra parte, Demeas en Adelphoe educa a uno de sus hijos duramente, haciéndole trabajar en las fatigosas tareas del campo; no obstante, el joven se extravía en andanzas libertinas (vv. 254-287); al final de la obra Demeas descubre los escándalos de su hijo; pero, disuadido por su hermano Mición de la severidad empleada a causa del pernicioso efecto que con ella ha logrado, pasa de un extremo al otro: de la rigidez máxima (que, por lo demás, es un claro exponente de la educación filial que solía impartirse en la Roma de la época de Terencio) a una indulgencia total que llega hasta el extremo de anular la autoridad paterna (vv. 776-997).

Ambos cambios de actitud, el de Menedemo en Heautontimorumenos y el de Demeas en Adelphoe, sin duda apuntan, desde nuestro punto de vista, al establecimiento en Terencio de una tercera modalidad en la presentación de las dicotomías que hasta ahora hemos venido observando.

Tras examinar las tres técnicas mediante las que, al parecer, Terencio imprimió un tono moralizante a la dinámica de su obra, nos surge de inmediato un interrogante casi insoslayable: ¿Dónde pretendía el comediógrafo llevar a su auditorio cuando le planteaba las tres clases de dicotomías que hemos analizado ? ¿ No sería a que de la confrontación de dos posturas opuestas, como hemos visto darse en las tres técnicas observadas, pasase el espectador a considerar moralmente que ninguna de las dos era la mejor, sino la que supuestamente podría establecerse, como término medio, entre la una y la otra?

Si se admitiera esta hipótesis, preciso sería concluir del análisis verificado que toda la obra de Terencio está impregnada del principio condensado en la sentencia ne quid nimis ("de nada demasiado"), principio corrientemente identificado, por su sabor ecléctico, con la máxima aristotélica comúnmente divulgada de que "en el término medio está la virtud".

$\mathrm{Y}$ en efecto, no bajo otro prisma parece que haya que enjuiciar el problema de la formación de conciencia que nos pone de relieve Menedemo en Heautontimorumenos; ni desde otra perspectiva podría verse el problema de la integración de la familia que nos presenta Hecyra, ni 
tampoco a consideraciones distintas da lugar el problema de la educación de los hijos en Adelphoe.

III. ¿ De todo esto qué mérito se desprende para Terencio? No, evidentemente, el de haber creado, pero sí, al menos, el de haber elegido, adaptado y encontrado en latín la forma que convenía para traducir la materia rica y delicada de sus modelos griegos. La comparación con las adaptaciones de Plauto, tan diferentes, permite delimitar su parte real de originalidad.

Homo sum: humani nihil a me alienum puto.

"Soy hombre y ninguna situación humana la considero ajena a mí."

Es el verso 77 de Heautontimorumenos que Terencio pone en boca de Cremes. La sentencia se ha citado tan frecuente y equivocadamente como la expresión de Antígona de participar en el amor y el odio. Su contenido no supone ningún programa; pero responde a una actitud ante la vida para la que los romanos acuñaron, a partir de la época de Terencio, el término humanitas que tanta vigencia tendrá en los siglos posteriores para designar la pervivencia del universalismo clásico.

De modo consecuente, el referido humanismo terenciano lo consideramos en nuestra opinión como factor determinante de la influencia que el comediógrafo va a ejercer en la tradición clásica del teatro europeo desde la Edad Media hasta nuestros días. Y una influencia tan prolongada es la que insoslayablemente nos lleva a sostener la tesis de que el carácter universal de las seis comedias terencianas queda al margen de toda discusión u objeción.

En efecto, en un anterior trabajo nuestro (Riquelme Otálora, 1983, v.2, p. 116) aludíamos a las repercusiones más conocidas y relevantes del dramaturgo en el teatro europeo medieval. Aunque un poco largo, reproducimos de nuevo aquí el texto de referencia como instrumento parcialmente corroborante de dichas repercusiones:

"Además de los numerosos comentarios antiguos y medievales que tomaron como objeto la obra de este dramaturgo, tan conocido como significativo resulta en la Edad Media el piadoso intento de la religiosa de Gandherseim Rosvita, que en el siglo X compone seis comedias a la manera de Terencio, pero de contenido cristiano, en su pretensión de atraer a los lectores que hacían sus delicias del poeta pagano con gran perjuicio de sus almas.

Tan elocuente como el de Rosvita es el caso del monje Notker Labeón que, también en Alemania y en plena Edad Media, traduce y vulgariza al poeta latino. En la misma línea de cristianizar a Terencio, aunque con alguna posterioridad en el tiempo-1592-, vuelve a la empresa en Holanda Cornelius Schonaeus de Haarlem, siguiendo los pasos de la ya citada monja Rosvita.

Y así pues, fué Terencio uno de los escasísimos autores antiguos que atravesaron incólumes la Edad Media".

Pero es Lisardo Rubio en el ya citado lugar (Rubio Fernández, 1966, v.1, p. LIV-LIX) quien ofrece la más completa información sobre la influencia de Terencio en las literaturas modernas:

"En el Renacimiento Terencio suscita el entusiasmo de Petrarca, J. Lipsio, Casaubón, Erasmo, Vives, Melanchtón, etc. A finales del siglo XVI se publica una antología de frases suyas con el título de Vulgaria Terenti, y su influencia es considerable en todas las literaturas europeas...

En Italia lo imita repetidas veces y, en ocasiones, muy de cerca Ludovico Ariosto (14741533): los caracteres de Volpino y Nebbia en la Cassaria (1508) son un calco de Davo y Sosia en Andria; la primera escena del acto II es traducción casi literal de Heautontimorumenos II, 3; en los Suppositi (1509) modela el tipo del padre Eróstrato sobre el Menedemo de Heautontimorumenos; la misma comedia encierra también algunos elementos tomados de Eunuchus; y, en fin, en Negromante (1530) contamina situaciones de Andria, Phormio y Hecyra. Lorenzino de Medici (1514-1548) imita Adelphoe en su Aridosia (1536). I Gelosi (1545), de V. Gabiani, contamina Andria y Eunuchus. Benedetto Varchi (1503-1565) en la Suocera (1557) traduce a veces y sigue siempre paso a paso la Hecyra latina. En fin, G. M. Cecchi (1518-1587) en su Moglie y sus 
Dissimili reproduce varias escenas terencianas de Andria y Adelphoe respectivamente.

En Francia es bien conocida la influencia que ejerce Terencio sobre Molière: $L$ 'école des maris (1661) tiene un argumento análogo al de Adelphoe y Les fourberies de Scapin (1671) imita al Phormio. El gran fabulista La Fontaine (1621-1695) pretendió adaptar Eunuchus a la escena francesa; su Eunuque (1654) es, según propia confesión, vulgar copia de un excelente original. La comedia, en colaboración, de Brueys y Palaprat titulada Le Muet (1691) es otra adaptación de Eunuchus. Baron (1653-1729), actor y autor dramático, discípulo de Molière, representa en París una Andrienne en 1703 y unos Adelphes en 1705. A mediados del siglo XVIII Fagan (1702-1755) tiene presente el Heautontimorumenos en la composición del Inquiet. Y en fin, en pleno siglo XIX logra en París un éxito L'Eunuque de Michel Carré (1845).

En Alemania ya citamos el caso de Rosvita. También en plena Edad Media traduce y vulgariza al poeta latino el monje Notker Labeón (950-1022); pero su influencia es considerable, sobre todo desde finales del siglo XV, y se acentúa con Melanchtón (1497-1560) y Hans Sachs (1494-1576). Más tarde Goethe (1749-1832) en su juventud toma a Terencio como modelo y cuando, ya en la edad madura, es director del teatro de corte, hace representar en Weimar Andria, Eunuchus y Adelphoe, traducidos y adaptados por sus amigos (primeros años del siglo XIX).

En Holanda Cornelius Schonaeus de Haarlem vuelve a la idea de Rosvita publicando un Terentius Christianus en 1592.

El creador del teatro danés, L. Holberg (1684-1754) buscó su inspiración en Terencio.

En Inglaterra recordemos las adaptaciones o imitaciones de G. Chapman en All Fools (1599: analogías con Heautontimorumenos), de Ch. Sedley en Bellamira (1687: analogías con Eunuchus), de R. Steele en Conscious Lovers (1722: analogías con Andria) y de E. Moore en Foundling (mediados del siglo XVIII).

En España ya el Marqués de Santillana lo cita repetidas veces como autor que le es familiar. Justifica el título de su Comedieta de Ponza, que nada tiene de dramático, con el precedente de Terencio «Peno» y Dante (ver el prohemio de la referida obra). También en el prólogo de los Proverbios de gloriosa e fructuosa enseñanza señala al comediógrafo latino como una de sus fuentes al lado de Platón, Aristóteles, Sócrates, Virgilio y Ovidio. Recoge efectivamente algunos de los consejos contenidos en Heautontimorumenos y Adelphoe.

Torres Naharro está muy imbuído de las ideas de Plauto y Terencio. «Aunque no imitara de propósito ninguna comedia latina, su pensamiento estaba fijo en ellas... Clásicos son los principios dramáticos expuestos en el prohemio de la Propaladia; clásicas las autoridades que se alegan; clásica la división en cinco actos y el uso de introitos y argumentos.» (Menéndez y Pelayo). Pero, si es evidente que Torres Naharro debe a la antigüedad clásica el concepto básico que de la comedia tiene, es también cierto que sus argumentos son originalísimos; y así resulta difícil precisar lo que en el detalle de su obra puede calificarse de imitación concreta de Plauto o Terencio. Sería precisa una revisión de sus comedias para indicar en ellas las reminiscencias terencianas, como se han señalado ya las plautinas. La Calamita, relacionada con Heautontimorumenos y Eunuchus es la más terenciana de las comedias de Torres Naharro.

La influencia de Terencio en La Celestina es bien conocida. La derivación terenciana fué ya indicada por el imitador más antiguo de La Celestina, el aragonés Pedro Manuel de Urrea, en el prólogo de la Penitencia de Amor (1514): «Esta arte de amores está ya muy usada en esta manera ... por çenas que dize el Terencio, y naturalmente es estylo del Terencio lo que hablan en ayuntamiento». La tragicomedia de Calixto y Melibea no repite ninguno de los argumentos de la comedia latina. Rojas, como Torres Naharro, debe a Terencio «su concepción dramática, la técnica escénica, el arte de las situaciones, la infinidad y variedad de recursos artísticos para animar la escena ...». Entre los numerosos elementos de Terencio que pasaron a La Celestina, recordemos que son terencianos muchos nombres de la tragicomedia (Pármeno, Sosia, Crito, Traso, Cremes, etc.), terencianos (o plautinos) los tipos de criados, rameras, etc. 
En España, como en toda Europa, fué Terencio uno de los autores más admirados y leídos en las escuelas. Los estatutos de la Universidad de Salamanca de 1538 prescriben que cada colegio represente, anualmente al menos, una comedia de Plauto o Terencio, y asignan un premio de seis ducados para el regente que mejor lo hiciere a juicio del rector y maestre escuela (título 61).

Terencio está presente en todo el siglo XVI y XVII. Obsesiona incluso a quienes pretenden deliberadamente sustraerse a su influencia, como sucede a Lope de Vega:

\section{$Y$ cuando he de escribir una comedia encierro los preceptos con seis llaves; saco a Terencio y Plauto de mi estudio para que voces no me den ...(Arte nuevo de hacer comedias, vv.40-44)}

A pesar de estas precauciones, varias reminiscencias de Andria y Heautontimorumenos se introdujeron en La guardia cuidadosa y La isla bárbara.

Cervantes presenta en La fuerza de la sangre un cuadro de familia análogo al ofrecido por Terencio en Hecyra, e igualmente el grupo Tomás de Avedaño, Constanza y Don Diego de Carriazo de La ilustre fregona tiene su paralelo en Pánfilo, Andria y Cremes de Andria.

Pero el Terencio de nuestra literatura es indudablemene Juan Ruiz de Alarcón. Este mejicano presenta notables analogías con el autor latino, incluso en su biografía: «ambos escritores vieron sus éxitos seriamente comprometidos por encarnizados enemigos que nunca perdieron ocasión de zaherirlos y vejarlos. Alarcón es nuestro Terencio por la profunda intención moral y por la urbanidad ática» (Menéndez y Pelayo); lo es por el acierto en la pintura de los caracteres y la universalidad de los pensamientos; lo es, en fin, por la distinción, sobriedad y pureza de su lengua. La obra maestra de Alarcón, La verdad sospechosa, debe a Terencio parte de su estructura, de sus tipos y situaciones.

Terencio es también maestro y modelo para Leandro Fernández de Moratín, el cual considera las comedias de Terencio como el prototipo del género. Se ha pensado a veces, equivocadamente, que el parecido entre ambos autores era indirecto y a través de Molière. Más que a Molière se parece Moratín al cómico latino. Moratín define la comedia pensando concretamente en las de Terencio, cuyo espíritu y técnica reviven en el autor hispano. «La musa de Moratín, suave, tímida, casta, parece que rehuye la expresión demasiado violenta, y guarda en el mayor tumulto de la pasión una compostura, una decencia, una flor de aticismo, como la que Terencio ponía hasta en sus esclavos y en sus rameras. Moratín es de la familia de Terencio, y en ambos la nota característica es una tristeza suave y benévola. No lo negará quien haya meditado el Sí de las niñas ...» (Menéndez y Pelayo).

Y en nuestros días, como se ha dicho, Jacinto Benavente «toma su poesía donde la encuentra », $i$ no habrá encontrado en Terencio el arte sutil, la moderación, la fina ironía, la sonrisa delicada, la concentración y penetración en el mundo interior que caracteriza a ambos autores?".

Tras la relación que precede de autores y obras que ponen de manifiesto en la totalidad de su conjunto la presencia y huella del comediógrafo latino, queda bien patente, y sin que quepa la menor duda al respecto, la innegable universalidad del teatro de éste como producto evidente del humanismo del que Terencio hace gala mediante la utilización consciente de los tres recursos dramáticos ya analizados, intencionadamente manejados por él en el transcurso de sus seis comedias ${ }^{4}$.

\section{Notas}

1- La traducción de cualquier cita aparecida es de nuestra entera responsabilidad.

2- Un esquema razonado que compendia las características generales de estos personajes sin 
atender a la diferente matización psicológica con que, por una y otra parte, los presentan Plauto y Terencio ha sido trazado por Agustín García Calvo en el prólogo con el que introduce su adaptación del Pseudolus de Plauto (p. 8); obra ésta que por lo demás aparece citada en la enumeración de las correspondientes referencias bibliográficas. Es interesante la confrontación de dicho esquema porque a partir de él y de los rasgos generales que allí aparecen vamos a establecer los diferentes matices psicológicos a que nos estamos refiriendo.

3 - Este trabajo fué defendido en la Universidad de Salamanca el 27 de junio de 1970 bajo el título de Esclavos y parásitos en el teatro de Plauto y Terencio, habiendo sido dirigido y orientado por la Dra. D Carmen Codoñer Merino, Catedrática de Filología latina de aquella Universidad.

4 - En el presente artículo ensamblamos algunas noticias de anteriores trabajos nuestros (J. Riquelme Otálora, 1983, v. 2, p. 115-120; y 1985, t. 11, f. 1 y 2, p. 9-29). Este ensamblaje no está exento, sin embargo, de la adición de nuevos datos y reflexiones que nos han conducido a complementar ahora en éste, e incluso a ampliar, las conclusiones y consideraciones obtenidas en dichos anteriores trabajos.

\section{Referências Bibliográficas}

ARNALDI, F. Da Plauto a Terenzio. v.2. Napoli, 1947.

BEARE, W. La escena romana. Traducción de E. J. Prieto. Buenos Aires, 1964.

BÜCHNER, K. Das Theater des Terenz. Heidelberg, 1974.

DUCKWORTH, G.E. The nature of roman comedy. Princeton, 1952.

FIELDS, D.E. Technique of exposition in roman comedy. University of Chicago, 1938.

FLICKINGER, R.C. On the originality of Terence. Philological quarterly, Iowa, v.7, p. 97-114, 1928.

FRANK, T. Terence's contribution to plot-construction. American journal of philology, Baltimore, v. 49, p. 309-323, 1928.

GARCÍA CALVO, A.: Cfr. PLAUTO.

GEOFFREY ARNOTT, W. Menander, Plautus, Terence. Oxford, 1975.

NORWOOD, G. The art of Terence. Oxford, 1923.

PARATORE, E. Storia del teatro latino. Milano, 1957.

PLAUTO, T.M. El Pseudolus o Trompicón. Introducción, versión rítmica y notas de Agustín García Calvo. Madrid: Cuadernos para el diálogo, 1971.

RIQUELME OTÁLORA, J. Técnicas de caracterización moral en los personajes terencianos. Actas del VI Congreso Español de Estudios Clásicos, Madrid, v. 2, p. 115-120, 1983.

RIQUELME OTÁLORA, J. Condiciones ambientales en los teatros de Plauto y Terencio. Cuadernos de investigación filológica, Logroño, t. 11, f. 1 y 2, p. 9-29, 1985.

RUBIO FERNÁNDEZ, L.: Cfr. TERENCIO.

TALADOIRE, B.A.Térence. Un Théâtre de la jeunesse, Paris, 1972.

TERENCE, P. Comédies. Introducción, establecimiento del texto y traducción de J. Marouzeau. 3 
ed. Paris: Les Belles Lettres, 1966.

TERENCIO, P. Comedias. Introducción, establecimiento del texto y traducción de L. Rubio Fernández. Barcelona: Alma Mater, 1966.

TERZAGHI, N. Prolegomeni a Terenzio. Roma, 1970.

Ponencia presentada en la Segunda Reunión Anual de la Sociedede Brasileira de Estudos Clássicos, celebrada en Belo Horizonte, los días 24-28 de agosto de 1987.

RIQUELME OTÁLORA, J. Humanism and universality in Terence's plays. Classica, São Paulo, 7/8:259-269, 1994/1995.

\begin{abstract}
Roman comedy with its about ten conventional types happens to be a faithful reflection of the social and economic classical world history, without any chronicles, systematization, neither a compilation by ancient historians. The two great latin comedy writers, though, deal, in a completely different way, with those same conventional characters. On the other hand, both wrote accordingly with the substantial different nature and aim between their works. This is to say: while Plauto's first purpose is to entertain his audience, by any means, Terence is determined to restyle on the scene the most subtle feelings of the human soul. This paper has intended to analyse and to work out the technical procedures Terence made use of in order that all the situations of his plays could reach the highest point of humanization. In our opinion, the important contribution of this work is that it stablishes the basis to explain the influence of Terence on the classical tradition of later european drama: not only medieval and along Renaissance, but also on modern and contemporary plays.
\end{abstract}

KEY WORDS: Terence, moral characterization techniques, humanism, classical tradition. 